\title{
Poor glycaemic control and its metabolic and demographic risk factors in a Malaysian community-based study
}

\author{
Daniel D. Reidpath ${ }^{1,2,3} \cdot$ Ireneous Soyiri $^{2}$ Nowrozy K. Jahan ${ }^{1,3} \cdot$ Devi Mohan $^{1} \cdot$ Badariah Ahmad $^{1} \cdot$ \\ Mohtar Pungut Ahmad ${ }^{4}$ Zaid Bin Kassim ${ }^{5}$ Pascale Allotey ${ }^{1,3,6}$
}

Received: 4 July 2017 / Revised: 3 November 2017 / Accepted: 7 November 2017 / Published online: 25 January 2018

(C) Swiss School of Public Health (SSPH+) 2018

\begin{abstract}
Objectives The lack of population-based evidence on the risk factors for poor glycaemic control in diabetics, particularly in resource-poor settings, is a challenge for the prevention of long-term complications. This study aimed to identify the metabolic and demographic risk factors for poor glycaemic control among diabetics in a rural community in Malaysia.

Methods A total of 1844 (780 males and 1064 females) known diabetics aged $\geq 35$ years were identified from the South East Asia Community Observatory (SEACO) health and demographic surveillance site database.

Results $41.3 \%$ of the sample had poor glycaemic control. Poor glycaemic control was associated with age and ethnicity, with older participants (65+) better controlled than younger adults (45-54), and Malaysian Indians most poorly controlled, followed by Malay and then Chinese participants. Metabolic risk factors were also highly associated with poor glycaemic control.

Conclusions There is a critical need for evidence for a better understanding of the mechanisms of the associations between risk factors and glycaemic control.
\end{abstract}

Keywords Glycaemic control · Health and demographic surveillance site · Metabolic risk factors · Ethnicity · Ecological factors

Pascale Allotey

pascale.allotey@unu.edu

1 Jeffrey Cheah School of Medicine and Health Sciences, Monash University Malaysia, Bandar Sunway, Malaysia

2 College of Medicine and Veterinary Medicine, The University Edinburgh, Edinburgh, Scotland, UK

3 South East Asia Community Observatory (SEACO), Monash University Malaysia, Bandar Sunway, Malaysia

4 Hospital Segamat, Ministry of Health Malaysia, KM 6 Jalan Genuang, 85000 Segamat, Johor Darul Takzim, Malaysia

5 Segamat District Public Health Office, Ministry of Health Malaysia, Peti Surat 102, Jalan Gudang Ubat, Kampung Gubah, 85000 Segamat, Johor Darul Takzim, Malaysia

6 United Nations University, International Institute for Global Health (UNU-IIGH),

UNU-IIGH Building, 56000 Bandar Tun Razak, Federal Territory of Kuala Lumpur, Malaysia

\section{Introduction}

The significance of the growing burden of diabetes in lowand middle-income countries (LMICs) is widely acknowledged (NCD Risk Factor Collaboration (NCDRisC) 2016). Worldwide, almost 500 million people were living with diabetes in 2014, an estimated prevalence of $8.5 \%$ among the adult population. In recent decades, the prevalence of diabetes has risen in low- and middle-income countries including Malaysia. The overall prevalence of diabetes mellitus (known and undiagnosed) among Malaysian adults of 18 years and above increased from $15.2 \%$ in 2011 to $17.5 \%$ in 2015 (Skriver et al. 2012; Lind et al. 2012). The recent National and Health Morbidity Survey also found an age-related trend in prevalence from $12.9 \%$ (95\% CI 11.1, 15.0) in the 35-39 years age group to $39.1 \%$ (95\% CI 33.6, 44.9) among the 70-74 years age group (Institute for Public Health 2015).

In the absence of a cure, the key to the long-term management of diabetes is individual glycaemic control. 
Poor glycaemic control increases the risk of all-cause mortality and morbidity (Skriver et al. 2012), including complications from cardiovascular disease (Lind et al. 2012; Nichols et al. 2013), kidney disease (Altemtam et al. 2012; Viswanathan et al. 2012), and eye disease (Takao et al. 2010; Salinero-Fort et al. 2013). There is a growing acceptance that community-based management of diabetes is the only cost-effective strategy, particularly in LMICs (Allotey et al. 2014a). Community-based management in this context refers to health system interventions that do not rely on clinical visits to health-care professionals. Interventions may range from group exercise programmes to smartphone app support (Mendes et al. 2017; Plotnikoff et al. 2017). The selection of a successful strategy requires an understanding of the ecological context in which disease is experienced, and the targeting of the risk factors that hamper effective control outside the clinical setting.

There is a substantial body of literature on metabolic and demographic risk factors for developing type 2 diabetes mellitus (T2DM) (DeBoer and Gurka 2017). There is also a significant body of research on the clinical management of T2DM, and an increasing body of research on community management of T2DM (Allotey et al. 2014a; $\mathrm{Ku}$ and Kegels 2015; Hou et al. 2016; DeBoer and Gurka 2017). This knowledge, however, does not extend to the LMIC context. Much of what we know about poor glycaemic control in people with diabetes comes from research in high-income countries (HICs). Given the disparity between the health systems of HICs and LMICs, the current evidence may not provide adequate data on which to plan for programmes in those places with the greatest burden (Allotey et al. 2014a).

Malaysia is ranked among the top ten countries in the world for the prevalence of T2DM, and it is expected to hold the rank until at least 2030 (Shaw et al. 2010). The T2DM challenge facing Malaysia is the same as that facing many LMICs: to find cost-effective ways to manage prevalent cases of diabetes within a health-care system originally designed for serial acute care (Allotey et al. 2011; Mustapha et al. 2014). There have been a handful of studies on glycaemic control in Malaysia (Ismail et al. 2011; Mahmood et al. 2016; Shu et al. 2017). These have been restricted to clinical populations, used inconsistent measures of glycaemic control, and in most cases utilised quite small sample sizes. There has also been a substantial audit of glycaemic control based on registry data, again from clinical settings (Chew et al. 2011).

The lack of community-based data on glycaemic control is a serious lacuna in the knowledge base. Studies of glycaemic control in clinical populations cannot adequately answer questions about the prevalence of, or risk factors for, poor glycaemic control in the population, because clinic attendees present an inherent self-selection bias and are either those concerned about their glycaemic control or those who are at more severe stages of the condition because of poor control. They therefore would not represent the population with the disease (Reidpath et al. 2016). Evidence from community-based research then becomes an essential element in any strategic, health systems approach to the management of diabetes. If identified risk factors are modifiable, there is the potential to develop targeted community-based interventions (e.g. Smalls et al. 2015; Mendes et al. 2017). If they are unmodifiable, they provide insights into likely future health services' demands. In this study, we examine the demographic and metabolic risk factors for poor glycaemic control, among people with T2DM who live in a rural district in the Malaysian Peninsula.

\section{Methods}

The study utilised data collected in 2013 as part of a crosssectional community health survey conducted in the South East Asia Community Observatory (SEACO) - a health and demographic surveillance site located in the Segamat District of Johor state in Peninsular Malaysia (Allotey et al. 2014b; Partap et al. 2017). The survey was of all individuals living in the enumerated community dwellings in the five sub-districts in which SEACO operates and conducted by trained data collectors. The Monash University Human Research Ethics Committee approved the study (20133837-3646).

The Segamat District has a mix of town, village and rural households with a network of government-run primary care clinics throughout the district and private medical providers in towns. It is a mixed economy with a substantial agricultural sector, mainly palm oil plantation. The SEACO site has ISO9001:2008 certification for its data collection and data management processes.

\section{Participants}

Only people aged $\geq 35$ years were eligible to contribute blood glucose data. The total sample of eligible participants was 18,767 , of whom 14,208 agreed to be interviewed-a rough response rate of $75.7 \%$. Of the respondents, 14,016 answered a self-report question for diabetes: "Have you ever been told by a doctor or other health worker that you have raised blood sugar or diabetes?" 1866 participants responded "yes" to this question; of whom 1844 provided a random blood glucose reading within the valid range of values for the glucometer (Fig. 1). These participants formed the final sample for the present study: 780 men and 1064 women. 


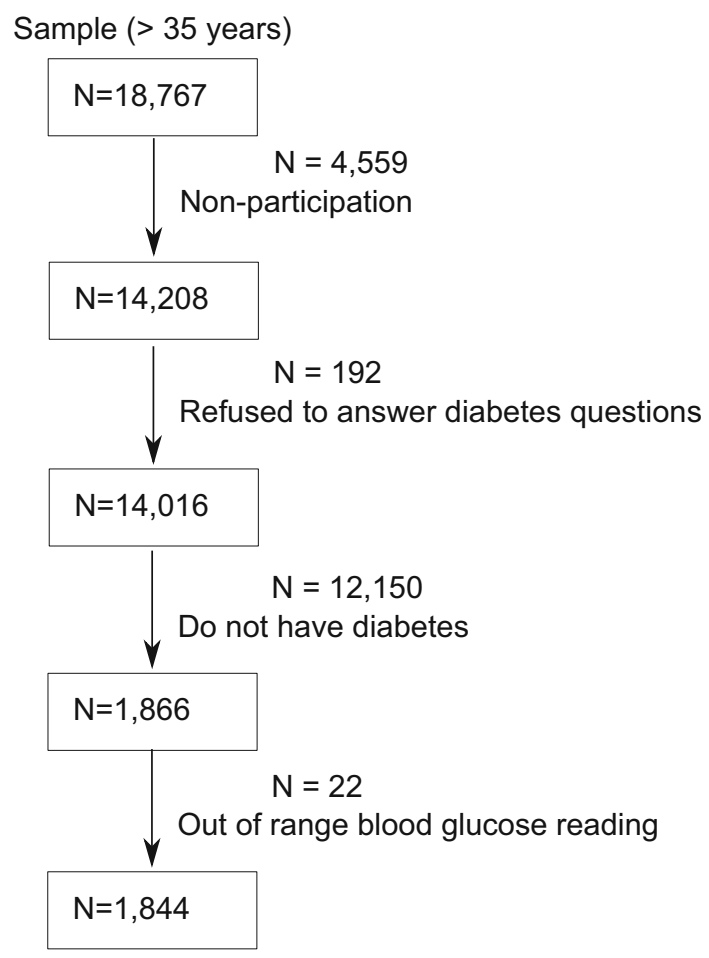

Fig. 1 Strobe flowchart (Malaysia 2013)

\section{Measures}

There is no standard for the measurement of glycaemic control. Glycated haemoglobin $\left(\mathrm{HbA}_{1 \mathrm{c}}\right)$ is the most common measure, capturing average blood sugar over the previous 2-3 months, but it misses the daily and weekly variation in blood glucose (Møller et al. 2013). Furthermore, even among researchers using $\mathrm{HbA}_{1 \mathrm{c}}$, there is no agreed cutoff for operationalising poor glycaemic control. Studies vary from a low threshold of $47.5 \mathrm{mmol} / \mathrm{mol}$ (6.5\%) through $58.5 \mathrm{mmol} / \mathrm{mol}(7.5 \%)$, and up to $69.4 \mathrm{mmol} / \mathrm{mol} \mathrm{(8.5 \% )} \mathrm{(Hasimah} \mathrm{Ismail} \mathrm{et} \mathrm{al.} \mathrm{2011;}$ Nichols et al. 2013; Shu et al. 2017).

The added complication in community-based studies of glycaemic control in LMICs is the cost and practicality of using $\mathrm{HbA}_{1 \mathrm{c}}$ (Reidpath et al. 2016). In earlier research, we established prediction equations for $\mathrm{HbA}_{1 \mathrm{c}}$ cutoff based on random blood glucose measures. A blood glucose cutoff of $\geq 11.4 \mathrm{mmol} / \mathrm{l}$ was shown to have perfect specificity (i.e. 1) for predicting $\mathrm{HbA}_{1 \mathrm{c}}>69.4 \mathrm{mmol} / \mathrm{mol}(8.5 \%)$, but with quite poor sensitivity $(0.37)$. While a point-in-time blood glucose measure is inadequate for individual clinical management, it can be used for population-based research. In the context of this study, a high cutoff threshold ensures that those identified with poor glycaemic control almost certainly do have it, and the cutoff is clinically associated with an increased risk of serious morbidity and mortality. (Nichols et al. 2013).
In consultation with the Ministry of Health's District Public Health Team, all participants in the study with a blood glucose $\geq 11.1 \mathrm{mmol} / \mathrm{l}$ were provided a referral to a government primary care clinic. A group of private family medicine practitioners also agreed to honour the referrals provided by the research team without cost to the patient. Blood glucose was estimated using a fingerprick (plasma) home monitoring glucometer (Omron model HGM-111).

The measured metabolic risk factors for a blood glucose $\geq 11.4 \mathrm{mmol} / 1$ were body mass index (BMI), blood pressure, and waist circumference. BMI was based on measured height and weight and was categorised based on World Health Organization, BMI categories for Asian populations into underweight $(<18.5)$, normal weight (18.5-21.99; reference category), overweight (22-25.99), Obese I (26-32.99) Obese II (33-36.99), and Obese III ( $\geq 37$ ) (WHO Expert Consultation 2004). Participants with a missing valid BMI value were included in the analysis as a separate category. Height and weight were estimated using electronic portable weighing scales with an electronic height sensor (Patient Focus, model GBS-721).

Blood pressure was measured at rest with an interval of 2 min between readings (Omron model HEM-7203) based on a validated strategy for community-based measurement (Reidpath et al. 2012). The three blood pressure measures were averaged and used to categorise diastolic and systolic blood pressure ( $\mathrm{mmHg}$ ) according to the following cutoffs: normotensive (systolic $<120$ and diastolic $<80$; reference category $), \quad$ pre-hypertensive $\quad(120 \geq$ systolic $<140$; $80 \geq$ diastolic $<90), \quad$ hypertensive $\quad(140 \geq$ systolic; $90 \geq$ diastolic). Participants with a missing valid blood pressure were included in the analysis as a separate category.

Waist circumference was measured based on a validated strategy for community-based measurement in a socially modest population using constant tension tape measures (Reidpath et al. 2013). Waist circumference measures were categorised based on recently published Malaysian cutoff values for cardiovascular risks (Cheong et al. 2014). A "higher-risk" waist circumference was $\geq 79.8 \mathrm{~cm}$ in women and $\geq 81.4$ in men; the reference category was the "lower-risk" group. Participants with a missing waist circumference measure were included in the analysis as a separate category.

The demographic risk factors included in the analysis were age, sex, ethnicity, marital status, and education level. Age was recorded in 10-year age categories (35-44, 45-54, 55-64 65-75, 75+); 45-54 years was the reference category. The reference category for sex was male. Ethnicity was categorised as Malay, Chinese (reference category), Indian, and others. Marital status was categorised as unmarried (reference category) and married. One participant with missing information on marital status was 
allocated to the most common category (married). Education was categorised as primary or less (reference category), secondary or more, and missing.

\section{Data analysis}

A preliminary analysis of the distribution of blood glucose values in the T2DM sample was conducted and then estimated for the population. A histogram of measured blood glucose values was created and overlaid with a logspline kernel density estimate of the population distribution of blood glucose values (Stone et al. 1997). Bootstrap aggregation (bagging) was used to estimate the final logsplines (Breiman 1996; Hastie et al. 2009), and the $95 \%$ credible intervals at each point were estimated from the pre-aggregated bootstrapped data.

Descriptive statistics for those with good and poor glycaemic control were calculated separately, and for the total sample, across the metabolic and demographic risk factors (Table 1).

A series of binomial, additive linear models was developed to explore the relationship between the demographic and metabolic risk factors and poor glycaemic control. The advantage of the additive binomial linear models is that risk differences can be estimated which are often of more interest and relevance than odds ratios (Kovalchik and Varadhan 2013; Kovalchik et al. 2013). We calculated unadjusted and adjusted risk differences for each of the demographic and metabolic risk factors in turn (Table 2). Finally, the Akaike information criterion (AIC) was calculated for the null model, the fully adjusted model, and a partial (interim) model containing only demographic predictors without metabolic predictors. Models with a better fit have a lower AIC.

All statistical analyses were conducted in the R statistical environment ( $\mathrm{R}$ Core Team 2017). The logsplines were estimated with the logspline package (Kooperberg 2016), and the additive binomial regression models were estimated using the blm package (Kovalchik and Varadhan 2013). A likelihood ratio test was used for the significance of the variables included in the adjusted model.

\section{Results}

The mean blood glucose value in the sample was $11.7 \mathrm{mmol} / \mathrm{l}(\mathrm{sd}=5.49 ; 95 \%$ CI $11.43-11.94)$ and the median was 9.9 (bootstrap 95\% CI 9.6-10.3), indicating a longer right tail to the distribution. Of the 1844 participants, 763 (41.3\%) had poor glycaemic control (95\% CI $39.1-43.7 \%)$. Figure 2 shows the histogram of measured blood glucose values overlaid with the kernel density (Stone et al. 1997). The sample median is marked with a dashed vertical line and poor glycaemic control cutoff (11.4 mmol/l) is marked with a solid vertical line.

Table 1 shows the distribution of participants (and percentage) stratified by glycaemic control, over the demographic and metabolic risk factors. A Pearson's Chi squared test for count data was calculated for each risk factor and the $p$ values are shown.

The majority of the participants were Malay, followed by Chinese and Indians. This is broadly consistent with the ethnic distribution in Malaysia. There was a significant association between ethnicity and glycaemic control, with Chinese participants least likely to have poor glycaemic control and Indian participants most likely to have poor glycaemic control. The modal age group was 55-64 years (38.4\% of the sample). There was a significant association between age group and glycaemic control, with older age groups appearing to have better glycaemic control. Women made up $57.7 \%$ of the sample; and most of the sample had primary or less education $(62.7 \%)$. There were no significant associations between the participants' sex or education and glycaemic control.

The modal blood pressure category was the "Missing" category, with participants with pre-hypertensive readings forming the next largest group (31.3\%). There was a significant association between blood pressure and glycaemic control. The majority of participants $(81.1 \%)$ had waist circumferences in the high-risk category. There was a significant association between waist circumference and glycaemic control. A substantial percentage (45.8\%) of the participants were in the Obese I, BMI category. Just under $60 \%(59.9 \%)$ of participant were in one of the three Obese BMI categories. There was no significant association between BMI and glycaemic control ( $p=0.131)$.

In the unadjusted binomial linear models, ethnicity and age were the only demographic risk factors significantly associated with poor glycaemic control. Indian ethnicity had an increased risk of uncontrolled diabetes compared with Chinese ethnicity (15.5\%; 95\% CI 7.1-24.0). Those aged $65-74$ or $75+$ had a reduced risk of poor glycaemic control compared with 45- to 54-year-olds: - 9.3\% $(95 \%$ CI -17.1 to -1.6$)$ and $-15.4 \%(95 \% \mathrm{CI}-25.3$ to $-5.6)$, respectively.

In the unadjusted models, all three metabolic risk factors were significantly associated with an increased risk of poor glycaemic control. Hypertension carried an increased risk of poor glycaemic control over normotension $(11.8 \%$; $95 \%$ CI 1.9-21.8). A high-risk waist circumference was associated with an increased risk of poor glycaemic control over a low-risk waist circumference $(11.3 \%$; $95 \%$ CI 4.3-18.3). Being overweight, Obese I, or Obese II carried an increased risk of poor glycaemic control over being normal weight, between $12.0 \%$ (overweight, 95\% CI 0.8-23.2) and 15.2\% (Obese I, 95\% CI: 4.5-25.8 and 
Table 1 The distribution of participants and percentages stratified by glycaemic control over the demographic and metabolic risk factors (Malaysia 2013)

\begin{tabular}{|c|c|c|c|c|c|c|}
\hline & \multicolumn{2}{|c|}{ Good control } & \multicolumn{2}{|c|}{ Poor control } & \multirow{2}{*}{$\begin{array}{l}\text { Total } \\
n\end{array}$} & \multirow[t]{2}{*}{$p^{* *}$} \\
\hline & $n$ & $\%$ & $n$ & $\%$ & & \\
\hline$n$ & 1081 & 58.6 & 763 & 41.3 & 1844 & \\
\hline \multicolumn{7}{|c|}{ Demographic risk factors } \\
\hline Ethnicity & & & & & & $<0.001$ \\
\hline Malay & 657 & 59.6 & 445 & 40.4 & 1102 & \\
\hline Chinese $^{\mathrm{a}}$ & 267 & 63.6 & 153 & 36.4 & 420 & \\
\hline Indian & 148 & 48.1 & 160 & 51.9 & 308 & \\
\hline Other & 9 & 64.3 & 5 & 35.7 & 14 & \\
\hline Age & & & & & & 0.001 \\
\hline $35-44$ & 79 & 57.7 & 58 & 42.3 & 137 & \\
\hline $45-54^{\mathrm{a}}$ & 211 & 54.4 & 177 & 45.6 & 388 & \\
\hline $55-64$ & 392 & 55.4 & 316 & 44.6 & 708 & \\
\hline $65-74$ & 288 & 63.7 & 164 & 36.3 & 452 & \\
\hline $75+$ & 111 & 69.8 & 48 & 30.2 & 159 & \\
\hline Sex & & & & & & 0.685 \\
\hline Male $^{\mathrm{a}}$ & 462 & 59.2 & 318 & 40.8 & 780 & \\
\hline Female & 619 & 58.2 & 445 & 41.8 & 1064 & \\
\hline Education & & & & & & 0.424 \\
\hline Primary $^{\mathrm{a}}$ & 674 & 58.3 & 483 & 41.7 & 1157 & \\
\hline Secondary & 367 & 60.1 & 244 & 39.9 & 611 & \\
\hline Missing/other & 40 & 52.6 & 36 & 47.4 & 76 & \\
\hline Marital status & & & & & & 0.414 \\
\hline Unmarried $^{\mathrm{a}}$ & 235 & 60.6 & 153 & 39.4 & 388 & \\
\hline Married & 846 & 58.1 & 610 & 41.9 & 1456 & \\
\hline \multicolumn{7}{|l|}{ Metabolic risk factors } \\
\hline Blood pressure & & & & & & 0.015 \\
\hline Normotensive $^{\mathrm{a}}$ & 142 & 62.0 & 87 & 38.0 & 229 & \\
\hline Pre-hypertensive & 348 & 60.3 & 229 & 39.7 & 577 & \\
\hline Hypertensive & 144 & 50.2 & 143 & 49.8 & 287 & \\
\hline Missing & 447 & 59.5 & 304 & 40.5 & 751 & \\
\hline Waist circumference & & & & & & 0.003 \\
\hline Lower risk $^{\mathrm{a}}$ & 177 & 68.3 & 82 & 31.7 & 259 & \\
\hline Higher risk & 853 & 57.1 & 642 & 42.9 & 1495 & \\
\hline Missing & 51 & 56.7 & 39 & 43.3 & 90 & \\
\hline BMI class & & & & & & 0.131 \\
\hline Underweight & 17 & 68.0 & 8 & 32.0 & 25 & \\
\hline Normal $^{\mathrm{a}}$ & 69 & 71.9 & 27 & 28.1 & 96 & \\
\hline Overweight & 285 & 59.9 & 191 & 40.1 & 476 & \\
\hline Obese I & 479 & 56.7 & 366 & 43.3 & 845 & \\
\hline Obese II & 98 & 56.6 & 75 & 43.4 & 173 & \\
\hline Obese III & 51 & 59.3 & 35 & 40.7 & 86 & \\
\hline Missing & 82 & 57.3 & 61 & 42.7 & 143 & \\
\hline
\end{tabular}

** $p$ values associated with Pearson's Chi square values calculated for each risk factor

${ }^{a}$ Reference category in subsequent binomial linear models 
Table 2 Unadjusted and adjusted modelled risk differences of demographic and metabolic risk factor for poor glycaemic control, including $95 \%$ confidence intervals and $p$ values (Malaysia 2013)

\begin{tabular}{|c|c|c|c|c|c|c|}
\hline & \multicolumn{3}{|c|}{ Unadjusted models } & \multicolumn{3}{|c|}{ Adjusted model } \\
\hline & Estimate $^{\mathrm{b}}$ & $95 \% \mathrm{CI}$ & $p$ & Estimate & $95 \% \mathrm{CI}$ & $p^{* * *}$ \\
\hline \multicolumn{7}{|l|}{ Intercept } \\
\hline Adjusted model ${ }^{\mathrm{a}}$ & & & & 26.2 & 10.1 to 42.4 & 0.001 \\
\hline \multicolumn{7}{|l|}{ Ethnicity } \\
\hline Chinese & 36.4 & 31.1 to 41.7 & & & & 0.001 \\
\hline Malay & 4.0 & -2.3 to 10.2 & 0.217 & 2.2 & -4.1 to 8.5 & 0.498 \\
\hline Indian & 15.5 & 7.1 to 24.0 & 0.000 & 13.3 & 4.7 to 21.8 & 0.002 \\
\hline Other & -0.7 & -32.0 to 30.6 & 0.964 & -4.3 & -37.6 to 29.0 & 0.800 \\
\hline \multicolumn{7}{|l|}{ Age } \\
\hline $45-54$ & 45.6 & 39.8 to 51.5 & & & & 0.001 \\
\hline $35-44$ & -3.3 & -14.6 to 8.1 & 0.571 & -2.0 & -13.2 to 9.1 & 0.720 \\
\hline $55-64$ & -1.0 & -8.2 to 6.3 & 0.790 & -2.9 & -10.4 to 4.5 & 0.444 \\
\hline $65-74$ & -9.3 & -17.1 to -1.6 & 0.018 & -11.7 & -20.2 to -3.2 & 0.007 \\
\hline $75+$ & -15.4 & -25.3 to -5.6 & 0.002 & -18.1 & -28.8 to -7.4 & 0.001 \\
\hline \multicolumn{7}{|l|}{ Sex } \\
\hline Male & 40.8 & 36.8 to 44.8 & & & & 0.986 \\
\hline Female & 1.1 & -4.2 to 6.4 & 0.697 & 0.0 & -5.4 to 5.5 & 0.988 \\
\hline \multicolumn{7}{|l|}{ Education } \\
\hline Primary & 41.7 & 38.4 to 45.1 & & & & 0.02 \\
\hline Secondary & -1.8 & -7.4 to 3.8 & 0.526 & -5.5 & -11.8 to 0.7 & 0.083 \\
\hline Missing/other & 5.6 & -8.2 to 19.4 & 0.424 & 9.9 & -4.0 to 23.8 & 0.161 \\
\hline \multicolumn{7}{|l|}{ Marital status } \\
\hline Unmarried & 39.4 & 33.8 to 45.1 & & & & 0.725 \\
\hline Married & 2.5 & -3.9 to 8.8 & 0.449 & 1.1 & -5.7 to 7.8 & 0.758 \\
\hline \multicolumn{7}{|l|}{ Blood pressure } \\
\hline Normotensive & 38.0 & 30.7 to 45.3 & & & & 0.010 \\
\hline Pre-hypertensive & 1.7 & -6.9 to 10.3 & 0.700 & -0.8 & -9.1 to 7.6 & 0.854 \\
\hline Hypertensive & 11.8 & 1.9 to 21.8 & 0.020 & 10.6 & 0.7 to 20.4 & 0.036 \\
\hline Missing & 2.5 & -5.9 to 10.8 & 0.559 & 4.0 & -4.2 to 12.1 & 0.341 \\
\hline \multicolumn{7}{|l|}{ Waist circumference } \\
\hline Low risk & 31.7 & 25.3 to 38.0 & & & & 0.095 \\
\hline Higher risk & 11.3 & 4.3 to 18.3 & 0.002 & 7.9 & 0.0 to 15.8 & 0.048 \\
\hline Missing & 11.7 & -2.0 to 25.3 & 0.095 & 8.8 & -11.8 to 29.4 & 0.402 \\
\hline \multicolumn{7}{|l|}{ BMI category } \\
\hline Normal & 28.1 & 18.2 to 38.0 & & & & 0.721 \\
\hline Underweight & 3.9 & -19.6 to 27.4 & 0.747 & 2.2 & -19.5 to 24.0 & 0.840 \\
\hline Overweight & 12.0 & 0.8 to 23.2 & 0.035 & 8.3 & -2.5 to 19.2 & 0.131 \\
\hline Obese I & 15.2 & 4.5 to 25.8 & 0.005 & 9.1 & -2.0 to 20.2 & 0.109 \\
\hline Obese II & 15.2 & 2.0 to 28.4 & 0.024 & 7.2 & -6.6 to 21.1 & 0.306 \\
\hline Obese III & 12.6 & -3.2 to 28.3 & 0.117 & 4.7 & -11.4 to 20.8 & 0.568 \\
\hline Missing & 14.5 & 0.8 to 28.3 & 0.038 & 9.4 & -8.9 to 27.7 & 0.314 \\
\hline
\end{tabular}

$* * *$ The $t$ test is used to calculate $p$ values for individual factor levels of a variable against the reference category. A likelihood ratio test is used to test the overall significance of including a variable in the final model

${ }^{\mathrm{a}}$ The intercept for the adjusted model, representing the risk of poor glycaemic control in Chinese males aged 45-54 year of age, unmarried, with primary or less education, normotensive, with a low-risk waist circumference, and normal weight BMI category. The estimates in the adjusted model indicate the risk difference between the intercept with the addition of one of the risk factors

${ }^{\mathrm{b}}$ The estimates in the unadjusted models are the risk differences between any risk factor category and the reference category (intercept) for that risk factor 
Obese II, 95\% CI 2.0-28.4). Being Obese III was associated with a similar risk difference $(12.6 \%)$, but it was not significant (95\% CI -3.2 to 28.3 ).

In the adjusted model, ethnicity remained a significant demographic risk factor $(p=0.001)$. Specifically, Indian ethnicity had an increased risk of poor glycaemic control compared with Chinese ethnicity $(13.3 \%$; $95 \%$ CI 4.7-21.8). Older people had a reduced risk compared with 45- to 54-year-olds. Those aged 65-74 years old had a reduced risk of $-11.7 \%$ (95\% CI -20.2 to -3.2 ), and those aged $75+$ had a reduced risk of $-18.1 \%$ (95\% CI -28.8 to -7.4$)$. Neither BMI $(p=0.721)$ nor waist circumference $(p=0.095)$ was a significant metabolic risk factor in the adjusted models, but blood pressure was $(p=0.01)$. Hypertension carried a greater risk of poor glycaemic control compared with normotension, after controlling for the other risk factors $(10.6 \%$; $95 \%$ CI 0.7-20.4).

In a post hoc analysis, to overcome collinearity between BMI and waist risk, we examined the contribution of waist risk in the absence of BMI, and BMI in the absence of waist risk, while including all other variables. BMI remains a non-significant variable in the model $(p=0.196)$; however, waist risk is significant $(p=0.008)$.

The AIC for the fully adjusted model was much smaller than the AIC for the partial model, which was in turn much smaller than the AIC for the null model $\left(6075.5_{\text {Full }}<6122.6_{\text {Partial }}<6187.2_{\text {Null }}\right)$. The magnitude of the reduction in the AIC indicated that the fully adjusted model had the best fit even after taking into account the additional predictors in the model.

\section{Discussion}

In 2015, Johor State, where we conducted our study, had the third highest diabetes prevalence among the 11 Malaysian states [19.8\% (95\% CI 16.8-23.3)] (Institute for Public Health 2015). The aim of glycaemic control is to delay the onset of diabetes-related complications (diabetic retinopathy and nephropathy) and to reduce diabetic-related morbidity and mortality. In our study, we found that slightly less than half $(43.3 \%)$ of the participants had poor glycaemic control. A study conducted in Malaysia also found poor glycaemic control among the adult patients with T2DM in health-care settings (Mahmood et al. 2016), but there are no comparative data available from nonclinical settings.

It is clear from our data that even with a known diagnosis, and access to clinical care through primary healthcare clinics, individuals with diabetes struggle to maintain glycaemic control, and ethnicity plays a significant role. This finding is consistent with that of the Malaysian study

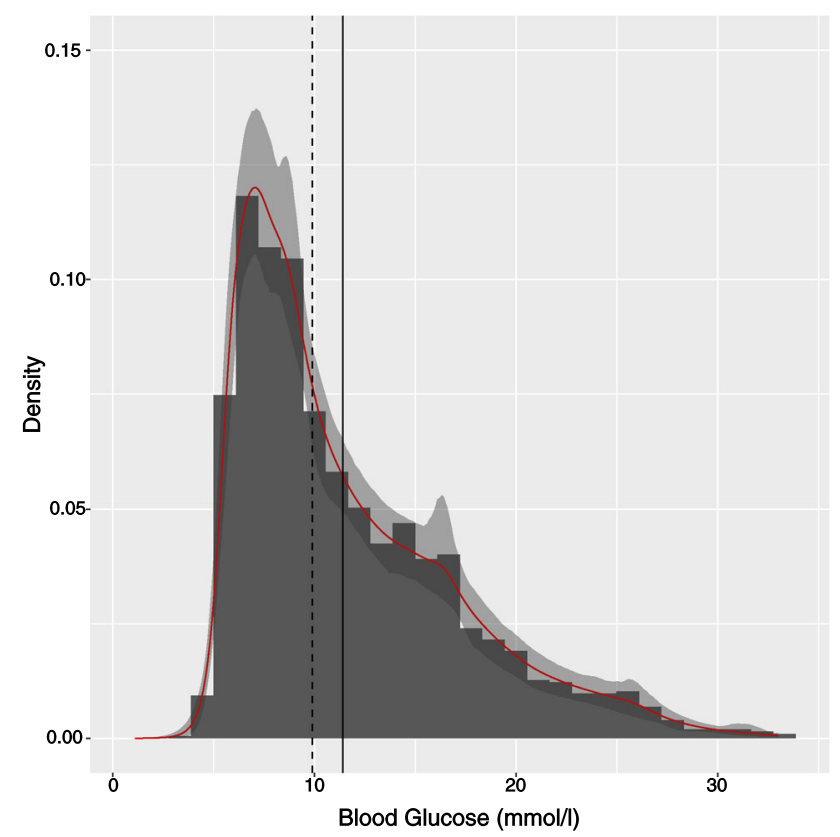

Fig. 2 Blood glucose and kernel density (Malaysia 2013)

based on the Adult Diabetes Control and Management Registry 2008-2009 and with the Singapore study on adult patients with T2DM (Sazlina et al. 2015; Tan et al. 2015). Indians have the highest risk for developing T2DM in Malaysia (Chew et al. 2011). Not only are Indians at greater risk of developing T2DM, they also appear to be at greater risk of having poor glycaemic control once they have developed diabetes. There has been some suggestion that the reason for this may be a physiological insulin resistance among the Indian ethnic group (Yeo et al. 2006). Indian adults are also less likely to engage in physical activity compared to Chinese, and the sedentary lifestyle further exacerbates poor glycaemic control (Tan et al. 2015).

In this study, age was also significantly associated with poor glycaemic control. Though the national diabetic prevalence increases with age (Institute for Public Health 2015), older age groups (65-74 and 75+ years) had a lower risk of poor glycaemic control compared with adult groups (45-54 years). A similar finding was reflected in a Singapore study where younger T2DM patients under 54 years had poorer glycaemic control compared to those who were 55 years and above (Tan et al. 2015). The reasons for this may relate to the duration of illness, differences in the types of medication, or patterns of accessing health services which are usually more frequent in older people. Age and ethnicity are unmodifiable risk factors; however, there is a potential here to explore in greater depth and through qualitative studies the related dynamics that hinder the management of glucose levels among 
diabetics in the community. Understanding this would then help to improve the appropriate targeting of interventions.

Malaysia, like many other middle-income countries, has a health system that provides care based on serial, acute episodes (Allotey et al. 2011). While there is a range of important new policies and interventions that take a broader public health approach to address the risk factors for non-communicable diseases like diabetes (Mustapha et al. 2014), these are not yet integrated effectively into primary care approaches for the management of individuals with non-communicable diseases. There have been some initial efforts to introduce models of integrated primary care to improve early detection of NCDs, but these again are unable to address secondary and tertiary prevention, the non-clinic based management and control for those diagnosed with diabetes. Ecological approaches could highlight the dynamic and complex processes through which the social environments and other contextual factors mutually affect the management of long-term disease (Rayner and Lang 2012). In real terms, this would require an understanding, for instance, about how families and households interact with and support disease management, as well as the effect of the person with diabetes on other members in the family and household. An ecological approach could further explore the impact of changes in health systems policy, financing and access on the ability to maintain glycaemic control, as well as provide critical information to health systems about the cost-effectiveness of various interventions.

\section{Limitations}

This study was conducted in a rural community in Malaysia, drawing on known diabetics in a fully enumerated population. The findings, in terms of prevalence rates, are not representative of the national population; nor are they intended to be. Like most health and demographic surveillance systems, the value of data collected in SEACO is in the capacity to explain population-level patterns and explore associations and relationships that help to inform policy directions and develop contextually relevant programs (Sankoh and Byass 2012).

The study would have been strengthened with data on duration of diagnosis, details of current treatment, and frequency of visits to primary care facilities. These variables will inform future more focused studies to enhance our understanding of glycaemic control.

A diagnosis of diabetes requires definitive and sustained lifestyle changes if a person with T2DM is to achieve adequate glycaemic control. In many cases, these changes can carry significant implications, not only for the individual, but also for the family and the social environment in which they engage. Changes may be needed for the whole family in relation to diets and engagement with cultural events and the control of obesogenic environments. The findings of this study highlight the need for a better understanding of the broader ecological drivers that would support better management of glycaemic control within the community. Without the ability to address structural- and environmental-level interventions, in addition to direct patient care the health burden of T2DM will increase over time and have significant implications for a responsive health system.

Acknowledgements The authors would like to express their appreciation to the SEACO Field Team and members of the SEACO Scientific Advisory Group from the Malaysian Ministry of Health. SEACO is funded by the office of the Vice Provost Research, Monash University Australia; the office of the Deputy Dean Research, Faculty of Medicine, Nursing and Health Sciences, Monash University Australia; the Monash Malaysia School of Medicine and Health Sciences and the Monash University Malaysia Campus. SEACO is an associate member of the INDEPTH Network.

\section{Compliance with ethical standards}

Ethics approval Ethics approval for the study was obtained through the Monash University Human Research Ethics Committee: MUHREC CF11/3663-2011001930 for the broader cohort and MUHREC CF13/439-2013000177 for the assessment of health status.

\section{References}

Allotey P, Reidpath DD, Yasin S et al (2011) Rethinking health-care systems: a focus on chronicity. Lancet 377:450-451. https://doi. org/10.1016/S0140-6736(10)61856-9

Allotey P, Davey T, Reidpath DD (2014a) NCDs in low and middleincome countries-assessing the capacity of health systems to respond to population needs. BMC Public Health 14:S1. https:// doi.org/10.1186/1471-2458-14-S2-S1

Allotey P, Reidpath DD, Devarajan N et al (2014b) Cohorts and community: a case study of community engagement in the establishment of a health and demographic surveillance site in Malaysia. Glob Health Action. https://doi.org/10.3402/gha.v7. 23176

Altemtam N, Russell J, El Nahas M (2012) A study of the natural history of diabetic kidney disease (DKD). Nephrol Dial Transplant Off Publ Eur Dial Transpl Assoc Eur Ren Assoc 27:1847-1854. https://doi.org/10.1093/ndt/gfr561

Breiman L (1996) Bagging predictors. Mach Learn 24:123-140

Cheong KC, Ghazali SM, Hock LK et al (2014) Optimal waist circumference cut-off values for predicting cardiovascular risk factors in a multi-ethnic Malaysian population. Obes Res Clin Pract 8:e154-e162. https://doi.org/10.1016/j.orcp.2013.03.004

Chew BH, Mastura I, Lee PY et al (2011) Ethnic differences in glycaemic control and complications: the adult diabetes control and management (ADCM), Malaysia. Med J Malays 66:244-248

DeBoer MD, Gurka MJ (2017) Clinical utility of metabolic syndrome severity scores: considerations for practitioners. Diabetes Metab Syndr Obes Targets Ther 10:65-72. https://doi.org/10.2147/ DMSO.S101624

Hastie T, Tibshirani R, Friedman J (2009) The elements of statistical learning: data mining, inference, and prediction, 2nd edn. Springer, New York 
Hou C, Carter B, Hewitt J et al (2016) Do mobile phone applications improve glycemic control (HbA1c) in the self-management of diabetes? A systematic review, meta-analysis, and GRADE of 14 randomized trials. Diabetes Care 39:2089-2095. https://doi.org/ $10.2337 / \mathrm{dc} 16-0346$

Institute for Public Health (2015) National Health and Morbidity Survey 2015, vol II. Non-communicable diseases, risk factors \& other health problems. Institute for Public Health, National Institutes of Health, Ministry of Health Malaysia, Kuala Lumpur

Ismail H, Hanafiah M, Saa'diah S et al (2011) Control of glycosylated haemoglobin (HbA1c) among type 2 diabetes mellitus patients attending an urban health clinic in Malaysia. Med Health Sci J 9:58-65

Kooperberg C (2016) logspline: Logspline Density Estimation Routines. Available from https://cran.r-project.org/web/ packages/logspline/index.html

Kovalchik SA, Varadhan R (2013) Fitting additive binomial regression models with the R package blm. J Stat Softw 54:1-18

Kovalchik SA, Varadhan R, Fetterman B et al (2013) A general binomial regression model to estimate standardized risk differences from binary response data. Stat Med 32:808-821. https:// doi.org/10.1002/sim.5553

Ku GMV, Kegels G (2015) Adapting chronic care models for diabetes care delivery in low-and-middle-income countries: a review. World J Diabetes 6:566-575. https://doi.org/10.4239/wjd.v6.i4. 566

Lind M, Olsson M, Rosengren A et al (2012) The relationship between glycaemic control and heart failure in 83,021 patients with type 2 diabetes. Diabetologia 55:2946-2953. https://doi. org/10.1007/s00125-012-2681-3

Mahmood MI, Daud F, Ismail A (2016) Glycaemic control and associated factors among patients with diabetes at public health clinics in Johor, Malaysia. Public Health 135:56-65. https://doi. org/10.1016/j.puhe.2015.07.043

Mendes R, Sousa N, Reis VM, Themudo-Barata JL (2017) Implementing low-cost, community-based exercise programs for middle-aged and older patients with type 2 diabetes: what are the benefits for glycemic control and cardiovascular risk? Int J Environ Res Public Health. https://doi.org/10.3390/ ijerph14091057

Møller JB, Overgaard RV, Kjellsson MC et al (2013) Longitudinal modeling of the relationship between mean plasma glucose and HbA1c following antidiabetic treatments. CPT Pharmacomet Syst Pharmacol 2:e82. https://doi.org/10.1038/psp.2013.58

Mustapha FI, Omar ZA, Mihat O et al (2014) Addressing noncommunicable diseases in Malaysia: an integrative process of systems and community. BMC Public Health 14:S4. https://doi. org/10.1186/1471-2458-14-S2-S4

NCD Risk Factor Collaboration (NCD-RisC) (2016) Worldwide trends in diabetes since 1980: a pooled analysis of 751 population-based studies with 4.4 million participants. Lancet Lond Engl 387:1513-1530. https://doi.org/10.1016/S01406736(16)00618-8

Nichols GA, Joshua-Gotlib S, Parasuraman S (2013) Glycemic control and risk of cardiovascular disease hospitalization and allcause mortality. J Am Coll Cardiol 62:121-127. https://doi.org/ 10.1016/j.jacc.2013.04.031

Partap U, Young EH, Allotey P, Soyiri IN, Jahan N, Komahan K, Devarajan N, Manjinder SS, Reidpath DD (2017) HDSS profile: the South East Asia community observatory health and demographic surveillance system (SEACO HDSS). Int J Epidemiol. https://doi.org/10.1093/ije/dyx113

Plotnikoff RC, Wilczynska M, Cohen KE, Smith JJ, Lubans DR (2017) Integrating smartphone technology, social support and the outdoor physical environment to improve fitness among adults at risk of, or diagnosed with, type 2 diabetes: findings from the 'eCoFit' randomized controlled trial. Prev Med. https:// doi.org/10.1016/j.ypmed.2017.08.027 (Epub ahead of print)

R Core Team (2017) R: a language and environment for statistical computing. R Foundation for Statistical Computing, Vienna

Rayner G, Lang T (2012) Ecological public health: reshaping the conditions for good health. Routledge, Oxon

Reidpath DD, Ling ML, Yasin S et al (2012) Community-based blood pressure measurement by non-health workers using electronic devices: a validation study. Glob Health Action 5:14876. https:// doi.org/10.3402/gha.v5i0.14876

Reidpath DD, Cheah JC-H, Lam F-C et al (2013) Validity of selfmeasured waist and hip circumferences: results from a community study in Malaysia. Nutr J 12:135. https://doi.org/10.1186/ 1475-2891-12-135

Reidpath DD, Jahan NK, Mohan D, Allotey P (2016) Single, community-based blood glucose readings may be a viable alternative for community surveillance of $\mathrm{HbA} 1 \mathrm{c}$ and poor glycaemic control in people with known diabetes in resourcepoor settings. Glob Health Action. https://doi.org/10.3402/gha. v9.31691

Salinero-Fort MÁ, San Andrés-Rebollo FJ, de Burgos-Lunar C et al (2013) Four-year incidence of diabetic retinopathy in a Spanish cohort: the MADIABETES study. PLoS One 8:e76417. https:// doi.org/10.1371/journal.pone.0076417

Sankoh O, Byass P (2012) The INDEPTH network: filling vital gaps in global epidemiology. Int J Epidemiol 41:579-588. https://doi. org/10.1093/ije/dys081

Sazlina S-G, Mastura I, Cheong AT et al (2015) Predictors of poor glycaemic control in older patients with type 2 diabetes mellitus. Singap Med J 56:284-290. https://doi.org/10.11622/smedj. 2015055

Shaw JE, Sicree RA, Zimmet PZ (2010) Global estimates of the prevalence of diabetes for 2010 and 2030. Diabetes Res Clin Pract 87:4-14. https://doi.org/10.1016/j.diabres.2009.10.007

Shu PS, Chan YM, Huang SL (2017) Higher body mass index and lower intake of dairy products predict poor glycaemic control among type 2 diabetes patients in Malaysia. PLoS ONE. https:// doi.org/10.1371/journal.pone.0172231

Skriver MV, Støvring H, Kristensen JK et al (2012) Short-term impact of HbA1c on morbidity and all-cause mortality in people with type 2 diabetes: a Danish population-based observational study. Diabetologia 55:2361-2370. https://doi.org/10.1007/ s00125-012-2614-1

Smalls BL, Walker RJ, Bonhila HS, Campbell JA, Egede LE (2015) Community interventions to improve glycemic control in African Americans with type 2 diabetes: a systemic review. Glob J Health Sci 7(5):171-182. https://doi.org/10.5539/gjhs. v7n5p171

Stone CJ, Hansen MH, Kooperberg C, Truong YK (1997) Polynomial splines and their tensor products in extended linearmodeling. Ann Stat 25:1371-1470

Takao T, Ide T, Yanagisawa H et al (2010) The effect of fasting plasma glucose variability on the risk of retinopathy in type 2 diabetic patients: retrospective long-term follow-up. Diabetes Res Clin Pract 89:296-302. https://doi.org/10.1016/j.diabres. 2010.03.027

Tan NC, Barbier S, Lim WY, Chia KS (2015) 5-Year longitudinal study of determinants of glycemic control for multi-ethnic Asian patients with type 2 diabetes mellitus managed in primary care. Diabetes Res Clin Pract 110:218-223. https://doi.org/10.1016/j. diabres.2015.07.010

Viswanathan V, Tilak P, Kumpatla S (2012) Risk factors associated with the development of overt nephropathy in type 2 diabetes patients: a 12 years observational study. Indian J Med Res $136: 46-53$ 
WHO Expert Consultation (2004) Appropriate body-mass index for Asian populations and its implications for policy and intervention strategies. Lancet Lond Engl 363:157-163. https://doi.org/ 10.1016/S0140-6736(03)15268-3
Yeo KK, Tai BC, Heng D et al (2006) Ethnicity modifies the association between diabetes mellitus and ischaemic heart disease in Chinese, Malays and Asian Indians living in Singapore. Diabetologia 49:2866-2873. https://doi.org/10.1007/ s00125-006-0469-z 